\title{
Journal of Management, Marketing and Logistics

\section{A COMPARATIVE ANALYSIS OF USER INSIGHTS FOR E-HEALTH DEVELOPMENT CHALLENGES IN TURKEY, KINGDOM OF SAUDI ARABIA, EGYPT AND UNITED ARAB EMIRATES}

\section{DOI: 10.17261/Pressacademia.2016219945}

\author{
N. Cigdem Isikdemir Uluc, Murat Ferman \\ Işık University. ncigdem.uluc@gmail.com \\ Işı University. mferman@isikun.edu.tr
}

\begin{abstract}
Implementation of e-health is expected to affect the outcomes of medical services positively, by contributing to the effectiveness and efficiency of overall healthcare ecosystem. This becomes more crucial in developing countries where access, finance, resources and competent professionals in healthcare are limited. This field study assesses healthcare professionals' insights, for the major challenges of ehealth development with a distinctive model and comparative analysis in four emerging countries; Turkey, Kingdom of Saudi Arabia, United Arab Emirates and Egypt. The research is conducted by user questionnaires and face to face interviews of healthcare professionals. Results indicate that information communication technology infrastructure, regulations, cultural and clinical adaptation of users, financing, supply chain management are some major challenges. Specially trust to e-business in healthcare, compliant use of big data in digital health and patient privacy play a key role for faster development of e-health.
\end{abstract}

Keywords: E-health, Emerging Countries, Patient Privacy, User Insights JEL Classification:

\section{INTRODUCTION}

Implementation and utilization of e-health in the healthcare sector, has great potential to improve healthcare practices in general. E-health with its broadest definition refers to the use of information technologies in healthcare services. It has a wide scope covering many concepts such as tele-health, mobile health, use of electronic health records, consumer health IT data and big data in digital health systems. In that respect implementation and use of big data in healthcare is one of the key pillars of e-health. Use of e-health becomes more crucial in developing countries, that are having many challenges in healthcare such as; access, financial needs, limitations in resources and healthcare professionals. Despite the efficiencies that e-health would bring to the healthcare system, there are still issues around investment and implementation decisions. These barriers become more remarkable in emerging countries where governments have initiatives for ehealth implementation and utilization. This explatory field study evaluates those major e-health challenges and needs for development in four selected emerging countries; Turkey, Kingdom of Saudi Arabia, United Arab Emirates and Egypt, based on user insights. The similarities and differences of e-health challenges across those selected countries are analyzed with a new framework of a solution model. This unique model is based on the outcomes of the field survey and face to face interviews conducted with clinicians, authorities of health ministries and healthcare information technology professionals in those selected countries. 


\section{LITERATURE REVIEW}

E-health in general terms is the use of digital information technologies in healthcare. WHO defines e-health as "the cost-effective and secure use of information and communication technologies in support of health and health-related fields, including health-care services, health surveillance, health literature and health education, knowledge and research" (WHO, 2005). E-health covers the development and use of a wide range of information and communication technology (ICT) systems for healthcare such as electronic health records, telemedicine, health information systems, mobile devices, e-learning tools, and decision support systems (Gerber et al., 2010). The rising demand and costs of healthcare, the need for more of qualified healthcare professionals, global technology requirements for faster and more accurate diagnostic and treatment, challenges of accessibility to rural areas encourage more use of digital technologies to improve and provide a more efficient healthcare service management (Global Healthcare Outlook 2020, 2015). In that respect the implementation and utilization of e-health is expected to impact those outcomes of healthcare services positively in terms of efficiency and effectiveness. Infact the number of reviews and meta-analyses on e-health interventions in patients with somatic diseases has increased considerably in recent years and most articles show that e-health is effective/cost-effective or at least suggest evidence is promising (Elbert et al., 2014).

Today healthcare systems recognise the value of existing and new data sources such as electronic health records, patient provided data creating governance to allow data access and sharing, form data partnerships and change on how care is delivered on the basis of data insights (Healthcare and Life Sciences Predictions 2020 A Bold Future, 2014). Therefore one can claim that the trend in healthcare is towards more use of information technology, handling healthcare data, decision support softwares for the clinicians, virtual hospital environments and availabilities for remote care. In many servicing and industrial fields, ICT (Information Communication Technologies) has been applied due to complications in the fields of health and treatment (Hossein, 2012). ICTs are potentially powerful instruments to strengthen health systems with innovations ranging from electronic health records to transmission of clinical data (Hossein, 2012). These technologies show great promise in low and middle- income countries (LMICs) whose health systems face severe financial, infrastructural, technical and human resource constraints; this is evident in the growing number of health service providers beginning to focus on mobile technologies to improve access and quality of health services (Schweitzer and Synowiec, 2012). Although e-health practices promise great improvement in healthcare, implementation and utilization of related policies still face some major challenges, especially in developing countries (Schweitzer and Synowiec, 2012). One of the reasons of those challenges might be due to ICT infrastructure readiness.

According to Anwar et al., (2012) and Kundi (2010), the developing countries do not have appropriate required infrastructure and professionals for e-health implementation and development. Therefore availability and effective use of ICT infrastructure is indispensable for successful adaptation of e-health systems (Qureshi et al., 2013). Developing countries are now waking up to the realization that they have to embrace information and communication technologies to deal with the problem of access, quality and costs of healthcare (Mugo and Nzuki, 2014). The adoption of ICT in health sector across developing countries will also accelerate knowledge diffusion and increase access to health information (Ojo et al., 2007). Another key challenge for e-health development and utilization in developing countries might be the lack of appropriate regulatory policies. According to Khoja et al., (2008) there needs to be policies at different stages of e-health planning process, and from different levels of decision makers. Use of e-health within or between institutions involves a number of factors that require proper planning and many of these issues can not be addressed without the support of well-defined policies, rules, standards, or guidelines at the institutional, jurisdictional, and global levels; it is therefore important to increase the awareness of health care providers and managers on e-health policy issues and provide them guidelines and support to develop those policies ( Khoja et al., 2008). 
Decision of financing e-health implementation would also be crucial for e-health development in a country and infact findings show that increased funding in health sector is strongly correlated with adoption of e-health even in the case of developed countries and this should also be the case for developing countries (Yu, 2012).

E-procurement or in other words an integrated supply chain management is another useful outcome of ehealth implementation and the optimization of procurement processes for medical and pharmaceutical products, helps hospitals reducing costs and increasing their cost transparency, treatment quality and patient safety (Bartsch et al., 2013). However, due to the great amount of actors and interfaces taking part in procurement processes a structured methodology is required for holistic documentation and analysis safety ( Bartsch et al., 2013) .

Another key discussion point of challenges for e-health implementation development, is the impact of trust to patient privacy and therefore the security of big data use in digital health. This is also one of the major interests of this distinctive field study. According to a literature review conducted by WHO (2012), the findings of the second global survey on e-health states that, respect and protection of, patient privacy has a well established history in global legal terms; it is generally accepted that such protection of privacy is not only a fundamental right of the individual, but also a core requirement of how health care is practiced therefore the respect for the privacy of the individual is crucial to the trust relationship between patient and healthcare-provider. This report further highlights that, the more recent literature covering scholars across disciplines of philosophy, sociology and medicine, have all noted that health care is changing ( WHO, 2012). It is moving from being based in a longterm relationship between a patient a small number of doctors to a series of shorter relationships with a much wide range of health-care professionals, which may be conducted online or on the phone as well as through more traditional face to face interaction; it is becoming more and more important to have a sound legal framework of privacy legislation directly applicable to healthcare as it is practiced today, whether that is in person or through an ICT medium ( WHO, 2012). Additionally the same report presents that almost $70 \%$ of the 113 responding countries have some sort of privacy legislation in place where the European Region has the highest uptake among WHO regions.

A further analysis of the responses shows that in general higher income countries have a higher prevalence of legal protection of patient privacy than lower income countries ( WHO, 2012). Privacy and trust are inextricably linked in healthcare and therefore public trust especially healthcare professional engagement in use of electronic health records for better healthcare delivery should be facilitated by clearer legal guidelines on rights and duties (WHO, 2012). Infact privacy and security are critical success factors in the movement toward EHR adoptation (Rinehart et al., 2009). In that respect handling healthcare data becomes so crucial. The internationally recognized interoperability standards emerge which in turn enable the adaptation of integrated electronic health records that are still one of the key area that needs improvement (Global Healthcare Outlook 2020 , 2015). For the development of e-health, apart from the ICT infrastructure readiness, the acceptance of any information system requires proper planning and management for change in an organisational context (Calloni, 2006). It is also crucial when introducing a new technology that changes the core processes of an organization, such as an e-health initiative: it is important that the structural design and culture of the organization is aligned with the predominant national culture in which the organization is embedded (Doktor, 2005). Actually with electronic health records implementations, change occurs not simply due to the introduction of ICT infrastructure but also because the job design of interconnected health professionals should be reengineered to effectively and efficiently accomodate the technology (Ford, Menachemi, and Philips, 2006). Use of big data in digital health, especially implementation of electronic health records for a national health system has many advantages for the governments, guiding and planning the public health policies. According to Szelak (2014), the last two decades have seen an explosion in big data throughout the healthcare value chain, as well as the advent of new platforms, tools, and methodologies in storing, structuring, and analysing big data. Important developments include the use of genomic data in drug discovery, the sharing of clinical-trial data, the use of electronic healthcare records (EHRs), and the increased availability of data from mobile health applications, patient registries, and social media (Szlezak, 2014). 
EHRs are the infrastructure for a well-structured, regulated, interoperable electronic national health records (ENHR). As stated by Reid et al., for building electronic national health records, there needs to be a national health information infrastructure (Reid et al., 2005). Today many developed countries progressed in terms of building their national health information systems whereas this is still in progress or at beginning level for many emerging countries where governments have planned actions for e-health implementation and utilization. It is crucial to know the challenges to be faced and solved for a successful implementation and development of e-health. This is even more important in developing countries, where uncertainity and instability are common (Luna et al., 2014). In the absence of solid evidence of its effects, key decision makers may doubt the effectiveness, which in turn, limits investment and in the long-term the integration of e-health services (Bergmo, 2015).

The above literature review presents a detailed evidence for the critical role of ICT infrastructure readiness, regulations, financing, supply chain management, clinical cultural adaptation, trust to patient privacy and related big data use in digital health for proper e-health development and utilization in a country. This review is also aligned with the initial face to face interviews conducted with some healthcare professionals in the selected countries, to assess the probable major e-health development challenges based on their insights. Therefore each of these highlighted challenges in literature is assigned to a hypothesis, to build a distintive model and is tested statistically. This is explained in detail in the section of data and methodology.

\section{E-health Initiatives in Selected Markets}

Before qualifying the e-health initiatives in selected markets that are in the scope of this study, it is worthwhile to give some brief global examples. Today European Commission has a concrete plan and roadmap for Europe which can be referred as Digital Agenda for Europe. Under this agenda it is clearly stated that information and communication technology for health and wellbeing (e-health) is becoming increasingly important to deliver top-quality care to European citizens (European Commission, 2015). The 'Digital Agenda for Europe' includes three specific actions on e-health, aimed at widespread deployment of telemedicine, patients' access to their health data and interoperability (European Commission, 2015).

UK is another highly developed country in Europe, in terms of ICT market and e-health practices. National Health Service (NHS) England is developing an NHS Technology Strategy and Roadmap, setting a national direction for NHS IT.NHS England has published its Business Plan for 2013-14 - 2015-16 called 'Putting Patients First', which explains how it will deliver its mandate from the government (European Commission, Putting patients in the driving seat: A digital future for healthcare, 2012). United States of America, Canada and Australia are other developed countries with high level of governmental e-health initiatives.

Turkey, Kingdom of Saudi Arabia, United Arab Emirates and Egypt are all emerging countries with governmental initiatives of e-health implementation at different levels. The efforts in Kingdom of Saudi Arabia for e-health practices go back to years 2000 when the government of Saudi Arabia formed a health reform committee to conduct a comprehensive review of the healthcare services provided to its citizens. The committee highlighted that a lack of proper health informatics was one of the top challenges facing the Saudi health. By 2005, SAHI which is the 'Saudi Association for Health Informatics' is established. By 2006 Saudi ehealth conferences have started which still have a good momentum to continue and host many visitors from different parts of the world (Altuwaijri, 2010). By 2008 there have been the attempts for setting up the national e-health programme. Actually it is planned in such a way that this programme is linked and coordinated with the Ministry of Health strategic objectives. Ministry of Health (MoH), Kingdom of Saudi Arabia, has launched the e-health programme and the related strategy in 2011 which has been planned to be implemented in two phases where each phase is referred as a five year programme. The official website of Ministry of Health, Saudi shares the business strategy with its related objectives and initiatives that can be obtained by e-health. The mission states to build a safe, quality health system based on patient centric care, guided by standards and enabled by e-health (Ministry of Health, Saudi official website , 2016). Similarly United Arab Emirates has an approved plan and a strategic roadmap to develop a national database of medical records to improve the quality of healthcare. E-health and health informatics are set as key initiatives within the 5 year strategic healthcare development plan launched by 2014 . 
Based on the feedbacks of UAE healthcare professionals the government is investing in integrated healthcare information systems to improve the overall quality of care and ensure patients' health and safety in Emirates. Health Authority Abu Dhabi ( HAAD) and Dubai Health Authority (DHA) are the two major healthcare authorities in UAE working on structured programs as a part of the overall health strategy towards integrated health informatics and e-health through improved information exchange.

The other emerging country within the scope of this study is Egypt. The Government of Egypt and its Ministry of Health have established several e-health programs to bring better diagnostic and health services to a wider segment of the Egyptian society. Ministry of Communication and Information Technology (MCIT) has facilitated the integration of information and communication technology (ICT) in health services and the provision of medical education to remote or underserved areas of Egypt. The e-health initiative is inspired by pursuing equal opportunities for health services anywhere in Egypt, and expanding medical insurance to all citizens (Ministry of Information and Communication Technology, Egypt , 2016).The principle objectives of the e-health initiatives in Egypt are mainly to extend better medical diagnostic services to rural areas, provide a training facility for medical community, reduce the cost of healthcare through better patient management, optimize utilization of expertise and resources and create electronic databases for medical records. Some of the main projects of this initiative are national network for citizen health treatment,women's mobile health unit project, IT health master plan, national picture archieving communication system (pacs) project and integrated national health record system (Ministry of Information and Communication Technology, Egypt , 2016).

Among these selected countries for the purpose of this field study, Turkey seems the most advanced, in terms of e-health implementation practices. The goal of Ministry of Health, Turkey is to build a national health information web system service, where all the services are based on open standards. The other major goal is to establish the electronic health records for more than 70 million Turkish citizens. (Ministry of Health Turkey, Department of Health Informatics, 2016).

The whole process of e-health is constructed under the umbrella of e-transformation in Turkey. E-health studies which are professionally conducted by the Turkish Ministry of Health are based on the 'Turkey Health Information System Action Plan' which has started in 2003 and has been completed in January 2004. To overcome the issue of quality data gathering, the National Health Dictionary ( HDD ) is developed and published in 2007, in the scope of the national e-health strategy. The National Health Data Dictionary (NHDD) aimed to ensure nation wide competability and interoperability of health information systems in Turkey (Yurt, 2008). For that reason first the digital health platform 'Sağlık Net' is built.Sağlık Net is the conversion of the existing networks into a true health network platform. It aims to link and manage the network of hospitals, family doctors, clinics, pharmacies, specialized hospitals and labs with standards and protocols; Tools such as national health digital dictionary, decision support systems, health insurance integration, electronic health records and also digital security systems e-signature) for patient privacy and data protection are key components for this network (Ministry of Health Turkey, Department of Health Informatics, 2016). 'Family Medicine Information System' (FMIS), has been the first successful result of this e-health initiative in Turkey. Following 'Saglık Net' in recent years"Saglik.NET 2" platform is established. "Saglik.NET 2 " is the platform where the data of family medicine information system and the data from the private hospitals, clinics and other healthcare entities that produce patient data are gathered . (Ministry of Health Turkey, Department of Health Informatics , 2016). Recently in 2015, Ministry of Health, Turkey has established a new online network for the Turkish Citizens called e-nabiz. This online system provides the opportunity for the national citizens to reach their personal health data with their own e-signature.

\section{DATA AND METHODOLOGY}

For the purpose of this field study four emerging countries; Turkey, United Arab Emirates, Kingdom of Saudi Arabia and Egypt are selected. The reason for selecting and comparing these countries, is primarily the similaries in the approach of governments for the development of e-health initiatives. These four countries have different level and extend of governmental e-health initiatives. The sample group of this research consists of clinicians, healthcare IT professionals and Ministry of Health executives who are either contributing or working on e-health initiatives in that country. Those participants of the study are also interviewed face to face. This sample group is referred as ehealth users in this study. 
The research is conducted by user questionnaires. A total of 251 e-health user questionnaires are collected for the analysis from those four selected countries. For each country 50 clinicians have replied the questionnaires. Additionally 15 healthcare IT professionals and Ministry of Health executives have also answered. The incomplete questionnaires are discarded of the statistical analysis. Two types of original questionnaires are used for the purpose of this research study. The questionnaires are prepared with the consultancy of some expert clinicians in the field of health informatics from the selected countries. The questionnaires are then tested with a selected group of healthcare professionals for the verification of the content, in order to maximize the outcomes of them to reflect useful data for this study and guide for any future user insight related e-health study.

Questionnaire I, is directed to clinicians and it consists of eleven closed end questions with a final comment section. These questions mainly target to identify the trust to e-business in healthcare, understand the status of use for e-health such as EHR and other healthcare IT practices in that hospital and qualify how effectively ehealth practices are performed in that hospital. This is linked with the identification of major challenges of ehealth development. In that respect ICT infrastructure readiness, clinical cultural adaptation, regulations, financing and supply chain management and trust to patient privacy and big data use in healthcare are given as independent variables for the respondent to quality in a range from strongly agree to strongly disagree. The questionnaire also evaluates the insights of e-health users for the expected benefits of e-health in their country as well as the approach and perceptions of clinicians to healthcare e-commerce as a part of e-health practices which is not covered in this paper and can be presented in the future.

Questionnaire II is directed to hospital healthcare information technologies (HCIT) professionals and also to Ministry of Health executives. It consists of eighteen closed end questions. The content of questionnaire II is the same as the questionnaire I which is for clinicians except there are additional questions to identify and analyze in depth the big data use, the trends and opportunities of big data and efforts for measurement of ehealth performance which are not again discussed and covered in this paper.Despite the complex structure and multi dynamics of e-health where e-health refers to all healthcare related e-business, there are some key contributors to the proper implementation and better utilization of e-health capabilities in a country. The preassessment based on e-health users' insights in this field study has indicated the essence of technology infrastructure and regulations with respect to compliant use of e-health. Trust to big data use and patient privacy, cultural adaptation of related e-health stakeholders such as clinicians, other hospital staff and patients are raised as strong contributors for e-health implementation and development. Many healthcare professionals have referred the significance of financing and supply chain management for e-health use and development. The literature survey also supports those arguments. Therefore based on this preassessment, a unique framework of a model is designed for assessing a country's e-health development and utilization capabilities as presented in figure 1. 
Figure 1: Proposed Conceptual Model of Framework for Assessing a Country's E-health Development

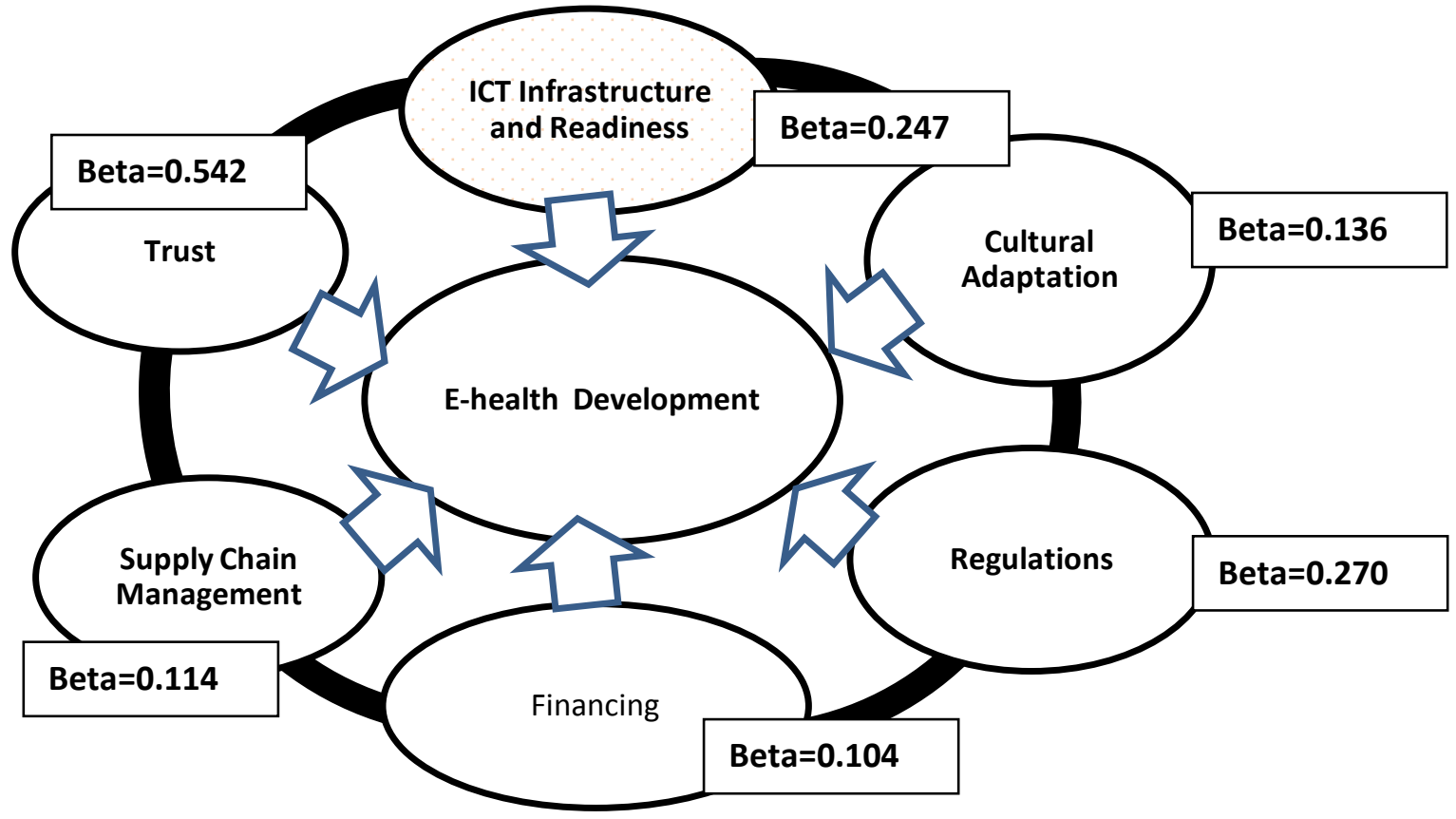

Depending on the model stated in figure 1 , the following hypotheses are formulated:

$\mathrm{H}_{1}$ : ICT infrastructure and readiness has a positive effect on e-health development.

$\mathrm{H}_{2}$ : Cultural adaptation has a positive effect on healthcare e-health development.

$\mathrm{H}_{3}$ : Governmental regulations, policies and standards have positive effect on e-health development.

$\mathrm{H}_{4}$ : Financing has positive effect on e-health development.

$\mathrm{H}_{5}$ : Supply chain management has a positive effect on e-health development.

$\mathrm{H}_{6}$ : Trust on online business has a positive effect on e-health development.

The above six independent variables are tested for the dependent variable 'e-health development' with multiple regression analysis. To test the hypotheses, the 251 questionnaires answered by selected e-health users from those four selected countries are analyzed. The answered questionnaires are considered as one sample. The participants have evaluated the independent variables in a range from agree to strongly disagree. The ANOVA table of the regression analysis is as presented in table 1.

Table 1: Results of ANOVA $^{\mathrm{a}}$

\begin{tabular}{|l|l|c|c|c|c|c|}
\hline \multicolumn{2}{|l|}{ Model } & Sum of Squares & Df & Mean Square & F & Sig. \\
\hline & Regression & 7,576 & 6 & 11,263 & 127,947 & , $^{\text {b }}$ \\
\hline 1 & Residual & 58,304 & 176 & 0,320 & & \\
\hline & Total & 65,880 & 182 & & & \\
\hline
\end{tabular}

a.Dependent Variable :Development of e-health practices

b.Predictors: ( Constant) Financing, ICT infrastructure readiness, clinical cultural adaptation, trust, supply chain management, governmental regulations. 
Since the significance ( $p$ value) of the model is $0,001(F=123,947)$ and is smaller than 0,05 , it can be concluded that the regression model is statistically significant. In other words, it is possible to explain the dependent variable e-health development by at least one of the independent variables. Collinearity may be one of the most important problems in multiple regression analysis. In order to check for collinearity VIF values may be analyzed. As can be seen from the table 2 below all the VIF values are below 10 pointing out that there are no signals for collinearity.

Table 2: Analysis of Collinearity, Coefficients ${ }^{a}$

\begin{tabular}{|c|c|c|c|c|c|c|c|c|}
\hline & \multirow{2}{*}{ Model } & \multicolumn{2}{|c|}{$\begin{array}{l}\text { Unstandardized } \\
\text { Coefficients }\end{array}$} & \multirow{2}{*}{$\begin{array}{c}\text { Standardized } \\
\text { Coefficients } \\
\text { Beta }\end{array}$} & \multirow{2}{*}{$\mathrm{T}$} & \multirow{2}{*}{ Sig. } & \multicolumn{2}{|c|}{$\begin{array}{l}\text { Collinearity } \\
\text { Statistics }\end{array}$} \\
\hline & & B & Std. Error & & & & $\begin{array}{c}\text { Toleranc } \\
\mathrm{e}\end{array}$ & VIF \\
\hline \multirow{7}{*}{1} & Constant & 3,687 & 1,285 & & 4,869 & 005 & & \\
\hline & Regulatory & 207 & 050 & 270 & 4,124 & 035 & 230 & 1,034 \\
\hline & Supply chain mng. & ,094 & 158 & 114 & 2,596 & ,002 & ,947 & 1,056 \\
\hline & Trust & ,533 & ,053 & ,562 & 8,628 & ,001 & 204 & 1,473 \\
\hline & $\begin{array}{l}\text { Clinical \&cultural } \\
\text { adaptation }\end{array}$ & ,098 & ,055 & 136 & 3,055 & ,000 & 260 & 1,845 \\
\hline & $\begin{array}{l}\text { ICT Infrastructure } \\
\text { readiness }\end{array}$ & 123 & ,061 & 247 & 3,385 & ,002 & ,554 & 1,807 \\
\hline & Payment/financing & ,076 & ,064 & 104 & 1,509 & 010 & 635 & 1,574 \\
\hline
\end{tabular}

a. Dependent Variable: e-health practices

Table 2 presents that, all of the significance values of independent variables are smaller than 0,05 which means all of the hypotheses are accepted. The standardized coefficients or Beta coefficients reveal the most effective variable on the dependent variable. It can be stated that trust $(B e t a=0,562)$ is the most effective variable for e-health implementation and development. It is followed by governmental regulations (Beta= 0,270), ICT infrastructure readiness (Beta $=0,247$ ), clinical and cultural adaptation (Beta $=0,136)$, supply chain management $($ Beta $=0,114)$ and financing $(B e t a=0,104)$ consecutively. Table 3 is the summary of the regression analysis for the model. From the table it is pointed out that, $R^{2}$ of the model is 0,499 , stating that this model explains nearly $50 \%$ percent of the variation in e-health development and implementation. In other words, the stated independent variables; trust, cultural adaptation, financing, regulations, ICT infrastructure and supply chain management explain the change in e-health development. The related table is as follows:

Table 3: Model Summary ${ }^{b}$

\begin{tabular}{|c|c|c|c|c|}
\hline Model & $\mathrm{R}$ & $\mathrm{R}$ Square & Adjusted R Square & $\begin{array}{c}\text { Std. Error of the } \\
\text { Estimate }\end{array}$ \\
\hline 1 &, $644^{\mathrm{a}}$ &, 499 &, 419 &, 38566 \\
\hline
\end{tabular}

a. Predictors: ( Constant), Financing, trust, ICT infrastructure readiness, clinical cultural adaptation, supply chain management, regulatory

b. Dependent Variable: Development in e-health practices

Based on the above results, all of the hypotheses are accepted. This states that if trust level to big data use and patient privacy in e-health will improve, e-health development and utilization in that country will also improve. Similarly If governmental regulations, cultural adaptation of clinicians and patients will improve, ehealth implementation will develop faster. The model also states that as those factors will not improve, the barriers for e-health improvement in that country will continue to exist. The model suggested above reflected 
that, it can explain the core reasons up to $50 \%$ in the dependent variable where the dependent variable is the challenges for development in e-health.

\section{Country Differences}

To qualify that there is a statistically significant difference between the countries in terms of those variables impacting the e-health development in a country, one-way anova is conducted.The following hypotheses are evaluated;

$\mathrm{H}_{1}$ : There is a statistically significant difference between countries in terms of the importance of regulations and policies for the development e-health.

$\mathrm{H}_{2}$ : There is a statistically significant difference between countries in terms of the importance of supply chain management for the development of e-health.

$\mathrm{H}_{3}$ : There is a statistically significant difference between countries in terms of the importance of trust to big data use and patient privacy for the development of e-health.

$\mathrm{H}_{4}$ : There is a statistically significant difference between countries in terms of the importance of financing for the development of e-health.

$\mathrm{H}_{5}$ : There is a statistically significant difference between countries in terms of the importance of clinical cultural adaptation for the development of e-health.

$\mathrm{H}_{6}$ : There is a statistically significant difference between countries in terms of the importance of ICT infrastructure readiness for the development of e-health.

To conduct Anova test, first of all test of homogeneity of variances is applied by Levene test to signify that the groups' variances for the selected variable are homogenous so that one-way anova test can be applied. Further, for multiple comparisons among countries the post hoc sheffe tests are conducted. The analysis have demonstrated that financing and supply chain management are not statistically significant. This also implies that clinicians perceive those challenges less important than the other encountered problems. This analysis has also presented the clinicians' view on ranking the challenges of e-health in their country. The challenges for e-health development are different for those selected countries in terms of priority. In parallel a second group of participants for this study consisting of healthcare IT professionals and Ministry of Health executives have replied the questionnaires for evaluating the challenges of e-health in their country. This provided an opportunity to analyze and compare the different views of healthcare professionals and evaluate the results respectively.

\section{FINDINGS AND DISCUSSIONS}

This field study presents an original framework of a model for assessing the major challenges of e-health development in emerging countries. The research is conducted in four emerging countries; Egypt, Kingdom of Saudi Arabia, Turkey and United Arab Emirates.The reason for selecting and comparing those countries, is primarily the similaries in the approach of governments for the development of e-health initiatives. The analysis is based on 251 user questionnaires that have been replied by a sample group of healthcare professionals consisting of selected clinicians, healthcare IT and Ministry of Health professionals. This distinctive model evaluates the contribution and impact of six major factors for e-health development in that country. Those factors are the infrastructure and communication technologies, cultural adaptation, government regulations, financing, supply chain management and trust to big data use and patient privacy in healthcare.In order to test the model, the data collected is treated as one sample independent of the countries. Then each country data is evaluated individually for comparison. The differences for primary challenges are analyzed by taking into account clinicians as well as healthcare IT and Ministry of Health executives' insights. The regression analysis has shown that, the model built to evaluate the major e-health challenges in selected emerging 
countries, has been statistically significant. It can be stated that trust to big data use and patient privacy in ehealth (Beta $=0,562$ ) is the most effective variable on e-health development. It is followed by governmental regulations where Beta is 0,270, further ICT infrastructure readiness (Beta=0,247), cultural adaptation of clinicians, other healthcare professionals and patients (Beta=0,136), supply chain management $(B e t a=0,114$ ) and financing (Beta $=0,104$ ) consecutively. As presented in Table 4, the comparative analysis has shown that, for Saudi clinicians the importance of trust to big data use for e-health development is high when compared to UAE clinicians (Mean=2,22<3,65) compared to Turkish clinicians (Mean=3,65>1,66) and Egyptian clinicians (Mean=3,65>2,12).

Table 4: Descriptives, Trust on Big Data Use and Patient Privacy in E-Health

\begin{tabular}{|c|c|c|c|c|c|c|c|c|}
\hline & \multirow{2}{*}{$\mathrm{N}$} & \multirow{2}{*}{ Mean } & \multirow{2}{*}{$\begin{array}{l}\text { Std. } \\
\text { Deviation }\end{array}$} & \multirow{2}{*}{ Std. Error } & \multicolumn{2}{|c|}{$\begin{array}{l}\text { 95\% Confidence Interval } \\
\text { for Mean }\end{array}$} & \multirow{2}{*}{ Minimum } & \multirow{2}{*}{ Maximum } \\
\hline & & & & & $\begin{array}{l}\text { Lower } \\
\text { Bound }\end{array}$ & $\begin{array}{l}\text { Upper } \\
\text { Bound }\end{array}$ & & \\
\hline UAE & 49 & 2,22 & ,971 & 139 & 1,84 & 2,40 & 1 & 5 \\
\hline Egypt & 49 & 2,12 & 971 & 139 & 1,84 & 2,40 & 1 & 5 \\
\hline Turkey & 50 & 1,66 & 939 & 133 & 1,39 & 1,93 & 1 & 5 \\
\hline Saudi & 49 & 3,65 & 1,011 & 144 & 3,36 & 3,94 & 1 & 5 \\
\hline Total & 197 & 2,39 & 1,226 & ,087 & 2,21 & 2,56 & 1 & 5 \\
\hline
\end{tabular}

Table 5 states that, the contribution of clinical cultural adaptation is perceived as a more important challenge and need for e-health development by Turkish and Egyptian doctors. UAE clinicians also emphasize the importance of clinical and cultural adaptation to use of e-health, as a major factor for e-health development in their country.

Table 5 Descriptives, Clinical and Cultural Adaptation to Use of E-Health

\begin{tabular}{|c|c|c|c|c|c|c|c|c|}
\hline & \multirow{2}{*}{$N$} & \multirow{2}{*}{ Mean } & \multirow{2}{*}{ Std.Deviation } & \multirow{2}{*}{ Std. Error } & \multicolumn{2}{|c|}{$\begin{array}{c}\text { 95\% Confidence Interval } \\
\text { for Mean }\end{array}$} & \multirow{2}{*}{ Minimum } & \multirow{2}{*}{ Maximum } \\
\hline & & & & & $\begin{array}{l}\text { Lower } \\
\text { Bound }\end{array}$ & $\begin{array}{l}\text { Upper } \\
\text { Bound }\end{array}$ & & \\
\hline UAE & 49 & 3,76 & 1,315 & 188 & 3,38 & 4,13 & 1 & 5 \\
\hline Egypt & 49 & 4,10 & 1,159 & 166 & 3,77 & 4,43 & 1 & 5 \\
\hline Turkey & 50 & 3,78 & 1,148 & 162 & 3,45 & 4,11 & 1 & 5 \\
\hline Saudi & 49 & 1,76 & 990 & 141 & 1,47 & 2,04 & 1 & 5 \\
\hline Total & 197 & 3,35 & 1,479 & 105 & 3,14 & 3,56 & 1 & 5 \\
\hline
\end{tabular}

Table 6 below presents that, for the UAE clinicians the importance of ICT infrastructure readiness for efficient e-health systems is high when compared to Saudi doctors (Mean=2,60>1,88).

For Turkish doctors the importance of ICT Infrastructure readiness for efficient e-health systems is high when compared to Saudi doctors (Mean=2,56>1,88). 
Table 6: Descriptives, ICT Infrastructure Readiness

\begin{tabular}{|c|c|c|c|c|c|c|c|c|}
\hline & \multirow{2}{*}{$\mathrm{N}$} & \multirow{2}{*}{ Mean } & \multirow{2}{*}{ Std. Deviation } & \multirow{2}{*}{$\begin{array}{l}\text { Std. } \\
\text { Error }\end{array}$} & \multicolumn{2}{|c|}{$\begin{array}{l}95 \% \text { Confidence Interval } \\
\text { for Mean }\end{array}$} & \multirow{2}{*}{ Minimum } & \multirow{2}{*}{ Maximum } \\
\hline & & & & & $\begin{array}{l}\text { Lower } \\
\text { Bound }\end{array}$ & $\begin{array}{l}\text { Upper } \\
\text { Bound }\end{array}$ & & \\
\hline UAE & 50 & 2,60 & 1,088 & ,154 & 2,29 & 2,91 & 1 & 5 \\
\hline Egypt & 49 & 2,51 & ,845 & 121 & 2,27 & 2,75 & 1 & 4 \\
\hline Turkey & 50 & 2,56 & 929 & 131 & 2,30 & 2,82 & 1 & 5 \\
\hline SAUDI & 49 & 1,88 & ,666 & ,095 & 1,69 & 2,07 & 1 & 3 \\
\hline Total & 198 & 2,39 & 937 & ,067 & 2,26 & 2,52 & 1 & 5 \\
\hline
\end{tabular}

As table 7 below displays, It can be stated that for Saudi doctors the importance of governmental regulations and policies for efficient e-health systems is higher compared to UAE clinicians (Mean=3,94>2,10), also higher from Egyptian clinicians (Mean=3,94>1,80) and higher from Turkish clinicians (Mean=3,94>2,22) considering their country and existing e-health practices.

Table 7: Descriptives, Regulatory

\begin{tabular}{|c|c|c|c|c|c|c|c|c|}
\hline & \multirow{2}{*}{$\mathrm{N}$} & \multirow{2}{*}{ Mean } & \multirow{2}{*}{ Std. Deviation } & \multirow{2}{*}{ Std. Error } & \multicolumn{2}{|c|}{$\begin{array}{l}\text { 95\% Confidence Interval } \\
\text { for Mean }\end{array}$} & \multirow{2}{*}{ Minimum } & \multirow{2}{*}{ Maximum } \\
\hline & & & & & $\begin{array}{l}\text { Lower } \\
\text { Bound }\end{array}$ & $\begin{array}{l}\text { Upper } \\
\text { Bound }\end{array}$ & & \\
\hline UAE & 49 & 2,10 & 1,159 & 166 & 1,77 & 2,43 & 1 & 5 \\
\hline Egypt & 49 & 1,80 & 957 & 137 & 1,52 & 2,07 & 1 & 5 \\
\hline Turkey & 50 & 2,22 & 790 & 112 & 2,00 & 2,44 & 1 & 5 \\
\hline SAUDI & 49 & 3,94 & 1,638 & 234 & 3,47 & 4,41 & 1 & 5 \\
\hline Total & 197 & 2,51 & 1,438 & 102 & 2,31 & 2,71 & 1 & 5 \\
\hline
\end{tabular}

In order to have a comparative analysis and a better understanding of each country's e-health development dynamics, the insights of healthcare IT professionals and Ministry of Health executives are evaluated separately from clinicians. Table 8 presents the results of this analysis. The respondents were allowed to pick more than one choice for ranking e-health challenges in their country. Therefore the total percentage does not add up to $100 \%$.

Table 8: Major Challenges of E-health Development; Insights of Healthcare IT Professionals and Ministry of Health Executives

\begin{tabular}{lcccc}
\hline & UAE & EGYPT & TURKEY & KINGDOM OF SAUDI ARABIA \\
\hline ICT Infrastructure & $2(70 \%)$ & $4(47 \%)$ & $5(33 \%)$ & $1(82 \%)$ \\
Clinical Cultural Adaptation & $1(80 \%)$ & $3(53 \%)$ & $4(40 \%)$ & $5(36 \%)$ \\
Regulatory policy and standards & $5(50 \%)$ & $5(33 \%)$ & $3(33 \%)$ & $2(64 \%)$ \\
Supply Chain Management & $7(50 \%)$ & $7(40 \%)$ & $7(67 \%)$ & $7(36 \%)$ \\
Financial investment & $6(40 \%)$ & $6(23 \%)$ & $6(67 \%)$ & $3(46 \%)$ \\
Trust to Patient Privacy & $3(40 \%)$ & $1(80 \%)$ & $1(68 \%)$ & $4(27 \%)$ \\
Trust to Security and Use of Big Data & $4(30 \%)$ & $2(40 \%)$ & $2(47 \%)$ & $6(27 \%)$ \\
\hline
\end{tabular}


Based on healthcare IT and Ministry of Health professionals' insights, patient privacy is the first major challange for proper e-health implementation in Turkey followed by trust to security of healthcare data. Regulatory policies and standards are ranked as third major challenge. Infact as highlighted in interviews of those healthcare professionals, proper regulations are expected to improve the security of digital big data in healthcare and trust to patient privacy in Turkey. Contrary to Turkish healthcare IT and Ministry of Health professionals, the Turkish clinicians perceive ICT infrastructure readiness and clinical cultural adaptation as more important challenges than trust to patient privacy and trust to security of healthcare data.

Egyptian healthcare IT and Ministry of Health professionals also state, trust to patient privacy and big data use in healthcare as top two priorities for development of e-health in Egypt. On the other hand similar to Turkish clinicians, Egyptian clinicians highlighted cultural and clinical adaptation as the major challenge for the development of e-health practices in Egypt.

According to Saudi healthcare IT and Ministry of Health professionals, ICT infrastructure readiness and the related regulations are the major challenges for e-health development in Kingdom of Saudi Arabia. Saudi clinicians have also raised the requirement of proper regulations for e-health development as the major priority. Contrary to Saudi healthcare IT and Ministry of Health Professionals, Saudi clinicians have ranked trust to patient privacy and big data use in healthcare as one of the top two major concerns for e-health development in Kingdom of Saudi Arabia. UAE healthcare IT and Ministry of Health professionals have ranked ICT infrastructure readiness and clinical cultural adaptation as the top two major challenges of e-health development in UAE. Trust to patient privacy and big data use in healthcare is ranked at third place.There is a consensus among UAE clinicians and UAE healthcare IT and Ministry of Health professionals as UAE clinicians have also ranked ICT infrastructure readiness and clinical cultural adaptation as top two major challenges for ehealth development in UAE. For both stakeholders of e-health in UAE, trust to patient privacy and trust to big data use in healthcare are the next major challenges of e-health development in UAE.

This field study has covered the insights of clinicians, healthcare IT and Ministry of Health executives in the selected countries with governmental e-health initiatives. On the other there are other stakeholders of ehealth such as patients and other healthcare staff. A bigger coverage of users is recommended for future research. The economical benefits of e-health is another field that needs to be investigated. It is expected to impact the investment decisions of governments for e-health in other many countries.

\section{CONCLUSION}

Innovation and new technology adoption are crucial for better and faster outcomes in healthcare. In that respect e-health has great potential to improve the quality and safety of healthcare. Use of e-health becomes more essential in developing countries where healthcare resources and medical services are limited. E-health can improve healthcare decision-making both for healthcare providers and patients, as well as providing speed and accuracy of information upon which healthcare decisions are made. Even if e-health would bring these types of efficiencies to the healthcare system, one can state that there are still challenges around investment and implementation decisions. These challenges become more remarkable in emerging countries where governments have initiatives for e-health implementation and utilization. Implementation and use of electronic health records and other digital health data are questioned by many stakeholders of e-health such as clinicians, patients and other healthcare professionals. That is mainly because of trust to patient privacy and security of data. Obviously this is closely linked with the proper regulations and policies to be put in place by governments. There are also other factors impacting e-health development, such as clinical cultural adaptation of clinicians, other healthcare staff and patients as major users of e-health. This paper presents an original field study by evaluating e-health challenges of development and its possible adaption capabilities in four selected emerging countries; Turkey, Kingdom of Saudi Arabia, United Arab Emirates and Egypt, based on user insights. A framework of a solution model is developed to identify the major challenges in selected countries. This unique model is based on the outcomes of the field survey and face to face interviews conducted with clinicians ,authorities of health ministries and healthcare IT professionals in selected countries. The expected factors of ehealth development in a country are put into hypotheses, they are tested and verified to be significantly contributing. This study also provides a comparative analysis between selected emerging countries in terms of e-health development needs by evaluating clinicians' views versus information technology healthcare 
professionals' views.Analysis of the model states that trust to use of big data and patient privacy is the major concern and challenge for e-health in all selected emerging countries based on user insights. ICT infrastructure readiness, regulations and policies for e-health are also highly impactful for e-health development. Clinical cultural adaptation of e-health stakeholders is another major contributor for improving e-health adaptation capabilities in a country. Financing for investment and proper supply chain management in e-health are other two crucial components for development. The comparative analysis among countries based on clinicians' view indicate the importance of regulations and trust to big data use and patient privacy for faster e-health development in Kingdom of Saudi Arabia. On the other hand Saudi healthcare IT professionals and Ministry of Health executives draw attention to ICT infrastructure readiness, financing as well as regulations for proper ehealth development in Saudi. Turkish and Egyptian clinicians raise trust to big data use and patient privacy as top two priorities for e-health development in those countries. There is a consensus among clinicians, healthcare IT professionals and Ministry of Health executives for both countries. UAE clinicians highlight the essence of ICT infrastructure readiness and also clinical cultural adaptation of users for improving development and adaptation capabilities of e-health in UAE which is also aligned with the other healthcare professionals' insights. In conclusion this research has drawn attention to essence of building trust to big data use and patient privacy in e-health development in selected countries. Based on healthcare professionals' view this would only happen with the aid of proper regulations and policies for e-health as well as the strong infrastructure for information and communication technologies. Finally as it is the case with every new technology, adaptation of users is critical. Therefore clinical cultural adaptation of users for e-health should be encouraged and supported by governmental policies.

\section{REFERENCES}

Altuwaijri, M. M. (2010). Supporting the Saudi e-health Initiative: the Master of Health Informatics Program at KSAU-HS. Eastern Mediterranean Health Journal, 16(1).

Anwar, F., Shamim, A., and Khan S. (2012). Barriers in adoption of health information technology in developing societies. International Journal of Advanced Computer Science, 2(1).

Bartsch, P., Lux, T., Wagner, A., and Gabriel., R. ( 2013). Wireless Mobile Communication and Healthcare/E-Procurement in Hospitals-An Integrated Supply Chain Management of Pharmaceutical and Medical Products by the Usage of Mobile Devices, pp.406-412

Bergmo, T. S. (2015). How to measure cost and benefits of e-health Interventions: An overview of methods and frameworks. Journal of Medical Internet Res 17(11):e254

Callioni, P. (2006). Successful Change Management, pp.1-31

Doktor, R. (2005). Organizational Learning and Culture in the Managerial Implementation of Clinical e-Health Systems: An International Perspective. Proceedings of the 38th Hawaii International Conference on System Sciences, pp.1-11

Elbert, NJ., Van Os-Medendorp, H., Renselaar, V.W., Ekeland, A.G., Hakkaart-van Roijen, L., Raat H, Nijsten, T.E. and Pasmans S.G. (2014). Effectiveness and cost-effectiveness of ehealth interventions in somatic diseases: a systematic review of systematic reviews and metaanalyses. Journal of Medical Internet Research, 16,

European Commission. (2012). Putting patients in the driving seat: A digital future for healthcare. European Commission Press Release.

European Commission. (2015). Digital Agenda for Europe, A Europe 2020 Initiative. European Commission, European Commission: https://ec.europa.eu/digital-agenda/en/eu-policy-e-health

Ford, E. W., Menachemi, M., and Philips, M. T. (2006). Predicting the adaptation of electronic health records by physicians: when will healhcare be paperless. Journal of American Medical Information Association 13(1), pp.106-112.

Gerber, T., Olazabal, V., Brown, K., Pablos-Mendez, A. (2010) An agenda for action on global e-health. Health Affairs, 29, 233-236. Doi:10.1377/hlthaff.2009.0934

Global Healthcare Outlook 2020. (2015). Deloitte Health Center for Solutions, pp.12-13

Healthcare and Life Sciences Predictions 2020 A Bold Future. (2014). Deloitte Health Center for Solutions.

Hossein, S. M. (2012). Consideration the Relationship between ICT and E-health. Journal of Biology, Agriculture and Healthcare, Vol 2 , No.8, pp.49-59. 
Khoja, S., Durrani, H., and Fahim, A. (2012). Scope of Policy Issues in eHealth: Results From a Structured Review. Journal of Medical Internet Research, Vol 14, No.1, pp. 1-26.

Kundi, GM. (2010). E-Business in Pakistan: Opportunities and Threats, Lap-Lambert Academic Publishing, Germany.

Luna, D., Almerares., Almerares, A., and Otero, C. ( 2014) Health Informatics in Developing Countries: Going beyond Pilot Practices to Sustainable Implementations: A Review of the Current Challenges. Journal of Healthcare Informatics Research, 20(1), pp.1-27

Ministry of Health Turkey, Department of Health Informatics . (2016). Ministry of Health Turkey, Department of Health Informatics : http://www.saglik.gov.trMinistry of Health, Saudi official website . (2016).

Ministry of Health, Saudi official website : http://www.moh.gov.sa/en/Pages/Default.aspx Ministry of Health, Strategic Plan 2010-2020. (2010).

Ministry of Health, Strategic Plan 2010-2020: www.msd.med.sa Ministry of Information and Communication Technology, Egypt . (2016).

Mugo, D. A., and Nzuki, D. (2014) Determinants of Electronic Health in Developing Countries. International Journal of Arts and Commerce $3(3)$, pp.49-60.

Ojo, A., Janowski. T., and Estrevez, E. ( 2007). Determining Progress Towards E-government: What are the Core Indicators? Japan:Center for Electronic Governance, United Nation University.

Qureshi, A. Q., Shah, B., Najeebullah., Kundi ,M. G., Nawaz, A., Miankhel,K., Christi, K.A. and Qureshi, A. N. (2013) Infrastructural Barriers to e-Health Implementation in Developing Countries. European Journal of Sustainable Development, 2(1), pp. 163-170

Reid, P., Fanjiang, G., Grossman, J., and Compton, W. (2005). Building a Better Delivery System: A New Engineering / Health Care Partnership, pp.1-276

Rinehart-Thompson, L.A., Hijort, B. M., and Cassidy, B. S. ( 2009 ) Redefining the Health Information Management Privacy and Security Role. Journal of Perspective Health in Management/ AHIMA, American Health Information Management Association, 6(1) pp. 1-26

Schweitzer,J., and Synowiec,C.(2012). The Economics of e-health and mHealth. Journal of Health Communication, pp.2-25.

Szlezak,N.,et al.,The role of big data and advanced analytics in drug discovery, development, and commercialization. Nature, 2014. 95(5): p. 492-5.

WHO. (2005). Resolution WHO 58.28. e-health. In: Fifty-eighth World Health Assembly. Geneva: World Health Organization, pp.108-110

WHO. (2012).Report Legal frameworks for eHealth: based on the findings of the second global survey on eHealth. Geneva: World Health Organization, pp. 5-71

Yu, P. (2012). Aged care IT in Australia - the past, present and future. Electronic Journal of Health Informatics, 7(2), e12

Yurt, N. (2008). Turkey's e-Health Activities: A Country Case Study,pp. 8-18 